\title{
The Telicity Parameter Revisited
}

\author{
Hana Filip \\ SRI International - NLP Group Discern \& Stanford University
}

\section{Introduction}

The goals of this paper are threefold: First, to review some recent syntactic accounts of cross-linguistic differences in the expression of telicity in Slavic vs. Germanic languages. Second, I will argue that the parametric variation in the encoding of telicity cannot be based on a unidirectional specifier head agreement between the verbal functional head linked to the telicity of the VP and the DO-DP in its specifier position, with languages exhibiting two clearly distinct modes of assigning telicity to the functional head. In the simplest terms, in Germanic languages, it is assigned by the DO-DP and in Slavic by the perfective/imperfective aspect of the lexical VP head. Rather, in a given telicity structure in both Slavic and Germanic languages, we actually observe mutual constraints and interactions between the head verb and one of its semantic arguments, namely, the incremental argument. Third, the variation in the encoding of telicity cannot be limited just to syntactic factors. Instead, it is semantic (and also pragmatic) factors that ultimately motivate (i) the phenomena that the syntactic parametric approach tries to capture, and also (ii) telicity phenomena that are a priori precluded by it, left out or unnoticed. In this connection, I will defend the familiar (though often forgotten) insights of Krifka's (1986 and elsewhere) and Dowty's (1991) mereological theory of telicity.

\section{The syntactic telicity parameter}

One dominant strand of research locates all variation in the encoding of telicity in syntax, with much of the work being motivated by assumptions of Minimalism and/or Distributed Morphology. Telicity is defined with respect to a dedicated syntactic structure, which typically involves a functional projection above the VP. It is identified with AspP ('aspect phrase', in Travis 1991, McClure 1994, Ramchand 1997, 2002, among quite a few others), AgrO ('object agreement', in van Hout 1992, 1996, 2000; Borer 1994, 1998; Ritter and Rosen 1998; Schmitt 1996, and others), $A S P_{Q}$ ('quantity aspect', in Borer 2004), or [telic] (in Kratzer 2004), for example. The grammar of Germanic languages requires that the morphosyntax of the DO-DP encode an instance of the telicity feature (e.g., a certain quantifier, article, or the accusative case), which forces it to enter an agreement relation with the functional head. The grammar of Slavic languages requires that telicity be assigned to the functional head by the perfective/imperfective morphology of the main lexical verb, which then binds the DO-DP in its specifier. Perfective heads uniformly assign the telic feature, and imperfective ones atelic. The telicity parameter is often illustrated with examples like the English and Russian ones in (1)-(3).

(1) a. Ivan ate soup *in ten minutes / for ten minutes.
b. Ivan jel ${ }^{\mathrm{I}}$ sup
*za desjat' minut
/ desjat' minut.
Ivan ate soup.SG.ACC $\quad *$ in ten minute.PL.ACC / ten minute.PL.ACC
'Ivan ate / was eating (the/some) soup for ten minutes.'

(2) a. Ivan ate the soup in ten minutes / for ten minutes.
b. Ivan $\underline{\mathbf{s}}-\overline{j e l}^{\mathrm{P}}$ sup sup za desjat' minut
$/ *$ desjat' minut.
Ivan CUL-ate soup.SG.ACC in ten minute.PL.ACC $/ *$ ten minute.PL.ACC
'Ivan ate up (all) the soup in ten minutes / *for ten minutes.'
'CUL' = culminative use of $s$ - 
(3) a. Ivan ate three pears in ten minutes / * for ten minutes.

b. Ivan tam na-stroil ${ }^{\mathrm{P}}$ mnogoetažek.

Ivan there CM-built many.floor.PL.GEN

'Ivan built a lot of highrises there.'

' $\mathrm{CM}$ ' = cumulative use of $n a-$.

Van Hout (in press), for example, takes as her point of departure contrasts like (1) and (2). According to her basic working hypothesis, in English (and also in Dutch), count versus mass noun morphosyntax of the direct object DP is taken to be correlated with the presence (2a) versus absence (1a) of articles, which determines the telic (2a) versus atelic (1a) interpretation of the VP, respectively. In Russian, the morphosyntax of the direct object does not matter, because it is the perfective/imperfective morphology of the main lexical verb that fully determines the telicity of the VP. The perfective marking by means of prefixes is correlated with the telicity of verbs and induces the countable specific interpretation of the mass direct object, as in (2b). This is significant, because Russian (just like other Slavic languages, with the exception of Bulgarian and Macedonian) lacks articles, which overtly mark the specific countable interpretation.

Borer (2004, Book II, Chapter 15) also includes examples like those in (3). Telicity, according to her, is identified with the cross-categorial property of 'quantity', manifested in nominal and verbal expressions. In English, it is assigned indirectly to $A S P_{Q}$ by the 'quantity' direct object DP: in (2a), 'quantity' is assigned by the definite article the (see Borer 2004, Book I, Chapter 6), and by the cardinal quantifier three in (3a). In Slavic languages, the quantity range is assigned directly to $A S P_{Q}$ by a set of head features, phonologically spelled out by prefixes, $s$ - in (2b) and $n a$ - in (3b), very much like the past tense marking is the phonological spell out of a tense head feature.

This emerging 'syntactic telicity parameter' has had impact beyond the boundaries of linguistics, and empirical evidence for it sought in psycholinguistic acquisitional studies. For example, van Hout (in press) proposes that "it is easier to learn telicity in languages or constructions that mark this property on the verb itself, such as perfective marking in the Slavic languages [i.e., by means of prefixes, HF] (...), than in constructions in which telicity has to be construed from the properties of the verb and its object, as in the Germanic languages and Finnish."

Among the questions the telicity parameter raises are the following ones: Is the parametric variation in the encoding of telicity limited to syntactic factors, or must semantic and pragmatic factors be taken into account, as well? Do languages only differ in the grammaticalization sources for telicity, without any substantial semantic and pragmatic differences among (fully developed) grammatical systems?

\section{The Notion of 'Telicity': Semantically-based Characterization}

I presuppose the general framework of event semantics with lattice structures (see Link 1983, 1987; Bach 1981, 1896). Inherently telic verbs denote (sets of) events, while verbs denoting (sets of) processes and states are atelic. Intuitively, an inherently telic verb like cross (oneself) refers to events that "can be directly or intrinsically counted", borrowing Mourelatos' (1981, p. 209) characterization: cp. He crossed himself three times. In contrast, the result of applying an iterative adverbial to an atelic verb like run is wellformed just in case the context determines what counts as 'one event' of running, otherwise it is ungrammatical: cp. (*)John ran three times last night. Bach $(1981,1986)$ proposes that the denotation of each event predicate has the structure of an atomic join semilattice, just like the denotation of each nominal count predicate, where the 'minimal' events denoted by verbs are the atoms and the 'non-minimal' events are the non-atomic 
elements. The denotation of a state or process verb has the form of a non-atomic (notnecessarily-atomic) join semilattice, just like the denotation of a nominal mass predicate. Hence, telicity is the marked case in the domain of verbal denotations, and atelicity unmarked (see also Partee 1999). In sum, an inherently telic verb denotes a set of atomic events (see Rothstein 2004, and related proposals in Mourelatos 1979/81; Bach 1981, 1986; Kiparsky 1998). Inherently atelic verbs lack this property, they are unmarked with respect to telicity.

The quantitative property of countability, which characterizes all telic predicates, has a rich variety of sources. There is a large class of telic predicates which derives it from one of their semantic arguments, which I will here call 'incremental argument'. This subclass of telic predicates can be characterized as in (5), based on some earlier suggestions by Krifka (1986 and elsewhere), Dowty (1991), Filip (1993/99, 2000) and Rothstein (2004):

(5) The meaning of a telic predicate is a homomorphism from the part structure of (the denotation of) its incremental argument into a part structure of events, and vice versa. The incremental argument provides a quantity criterion $Q C$ that contextually individuates countable (or atomic) events in the denotation set of a telic predicate.

The incremental argument is any semantic argument of a predication that provides a part structure suitable for an event measurement, i.e., for the application of some quantity criterion $Q C$ for a telic predicate, modulo pragmatic principles of interpretation and general knowledge about the typical or conventional course of events in the world (see Filip 1993/99 and Section 4 below). Paradigmatic $Q C$ incremental arguments are quantized, such as three pears in eat three pears in (3a). Krifka's (1986 and elsewhere) mereological definition of quantization is given in (6).

$$
\mathrm{QUA}(\mathrm{P}) \leftrightarrow \forall \mathrm{x}, \mathrm{y}[\mathrm{P}(\mathrm{x}) \wedge \mathrm{P}(\mathrm{y}) \rightarrow \neg \mathrm{y}<\mathrm{x}]
$$

A predicate $P$ is quantized if and only if no entity that is $P$ can be a proper subpart of another entity that is $\mathrm{P}$.

However, there are nominal predicates that fail to be quantized, when analyzed in isolation as predicates, and yet induce the telic interpretation of a complex verbal predicate they form (Partee p.c. to Krifka, Carlson, L. 1981, p. 54, Mittwoch 1988, p. fn.24, Dahl 1991, p. 815, Moltmann 1991, Zucchi \& White 1996, 2001, among others). Examples are nominal count predicates like ribbon or fence, predicates with vague measure phrases like $a$ large/small quantity of, or vague quantifiers like $a$ lot of. The need to overcome such problems related to the notion of 'quantization' motivated a number of fruitful discussions and alternative proposals (see Zucchi \& White ibid., Krifka 1997, 1998, Rothstein 2004 and Borer 2004, for example). The limits of this paper do not permit me to discuss any here, but it is certain that the incremental argument providing the quantity criterion $Q C$ for a telic predicate cannot be homogeneous. Homogeneity is defined in (7) as a conjunction of divisivity and cumulativity. (See also Krifka 1986, Moltmann 1991, Kiparsky 1998, and 'cumulative reference' in Quine 1960, p. 91.)

$$
\begin{aligned}
& \text { a. } \quad \operatorname{HOM}(\mathrm{P}) \leftrightarrow \mathrm{DIV}(\mathrm{P}) \wedge \mathrm{CM}(\mathrm{P}) \\
& \text { b. } \quad \operatorname{DIV}(\mathrm{P}) \leftrightarrow \forall \mathrm{x}, \mathrm{y}[\mathrm{P}(\mathrm{x}) \wedge \mathrm{y}<\mathrm{x} \rightarrow \mathrm{P}(\mathrm{y})] \\
& \text { c. } \quad \mathrm{CM}(\mathrm{P}) \leftrightarrow \forall \mathrm{x}, \mathrm{y}[\mathrm{P}(\mathrm{x}) \wedge \mathrm{P}(\mathrm{y}) \rightarrow \mathrm{P}(\mathrm{x} \oplus \mathrm{y})] \wedge \exists \mathrm{x}, \mathrm{y}[\mathrm{P}(\mathrm{x}) \wedge \mathrm{P}(\mathrm{y}) \wedge \neg \mathrm{x}=\mathrm{y}] \\
& \text { Examples: wine } \subseteq I \wedge \operatorname{HOM}(\text { wine }), \text { pears } \subseteq I \wedge \operatorname{HOM}(\text { pears })
\end{aligned}
$$

(6) and (7) define quantization and homogeneity as properties of predicates of individuals. They can be also defined as properties of predicates of eventualities. Quantized verbal predicates are telic, but not every telic predicate is quantized (see also Krifka 1998). For 
example, an expression like walk for an hour is telic but not quantized, because it may apply to two contemporaneous events and their sum. Homogeneous verbal predicates are co-extensive with atelic predicates: namely, process or state predicates.

It follows from the unmarked nature of atelic verbs and the definition of telic predicates given in (5) that any denotation of an atelic verb can serve as a basis for generating a telic predicate, provided it can be combined with a suitable incremental argument specifying the quantity criterion QC. (See Filip 1993/99 and Kratzer 2004 for similar proposals, and Section 4 below.) For example, in (3a), the result of composing an atelic verb like ate with the quantized incremental argument three pears is the quantized, and hence telic, predicate ate three pears. Intuitively, this follows given that every proper part of the denotation of three pears corresponds to exactly one proper part of the eating event, and vice versa. In (1a), ate maps some soup stuff and its subparts into the part structure of the denotation of ate soup, and vice versa. However, since soup does not specify a definite quantity of soup, ate soup is atelic. Formally, such relations may be represented by means of homomorphic mappings between the part structure of the referent of the direct object (three pears, soup) and the part structure of the event described by the VP (ate three pears, ate soup). (Other proposals can be found in Verkuyl 1972, 1993, 1999, and Jackendoff 1996, for example.) Such homomorphic mappings involve two central requirements: namely, mapping to subobjects (8a) and mapping to subevents (8b), defined in Krifka $(1992,1998)$.
a. mapping to subevents, iff $\forall \mathrm{x}, \mathrm{y} \in \mathrm{U}_{\mathrm{P}} \forall \mathrm{e} \in \mathrm{U}_{\mathrm{E}}\left[\mathrm{R}(\mathrm{x}, \mathrm{e}) \wedge \mathrm{y}<_{\mathrm{P}} \rightarrow \exists \mathrm{e}^{\prime}\left[\mathrm{e}^{\prime}<_{\mathrm{E}} \mathrm{e} \wedge \mathrm{R}\left(\mathrm{y}, \mathrm{e}^{\prime}\right)\right]\right]$
Whenever $\mathrm{R}$ holds for an object $x$ and an event $e$, then every proper part $y$ of $x$ stands in the relation $\mathrm{R}$ to some proper part $e$ ' of $e$.
b. mapping to subobjects, iff $\forall \mathrm{x} \in \mathrm{U}_{\mathrm{P}} \forall \mathrm{e}, \mathrm{e}^{\prime} \in \mathrm{U}_{\mathrm{E}}\left[\mathrm{R}(\mathrm{x}, \mathrm{e}) \wedge \mathrm{e}^{\prime}<_{\mathrm{E}} \mathrm{e} \rightarrow \exists \mathrm{y}\left[\mathrm{y}<_{\mathrm{P}} \mathrm{x} \wedge \mathrm{R}\left(\mathrm{y}, \mathrm{e}^{\prime}\right)\right]\right]$
Whenever R holds for an object $x$ and an event $e$, then every proper part $e^{\prime}$ of $e$, stands in the relation $\mathrm{R}$ to some proper part $y$ of $x$.
c. uniqueness of events, iff $\forall \mathrm{x}, \mathrm{y} \in \mathrm{U}_{\mathrm{P}} \forall \mathrm{e} \in \mathrm{U}_{\mathrm{E}}\left[\mathrm{R}(\mathrm{x}, \mathrm{e}) \wedge \mathrm{y} \leq_{\mathrm{P}} \mathrm{x} \rightarrow \exists\right.$ ! $\left.\mathrm{e}^{\prime}\left[\mathrm{e}^{\prime} \leq_{\mathrm{E}} \mathrm{e} \wedge \mathrm{R}\left(\mathrm{y}, \mathrm{e}^{\prime}\right)\right]\right]$
The subevents that correspond to subobjects are unique.
d. uniqueness of objects, iff $\forall \mathrm{x} \in \mathrm{U}_{\mathrm{P}} \forall \mathrm{e}, \mathrm{e}^{\prime} \in \mathrm{U}_{\mathrm{E}}\left[\mathrm{R}(\mathrm{x}, \mathrm{e}) \wedge \mathrm{e}^{\prime} \leq_{\mathrm{E}} \mathrm{e} \rightarrow \exists ! \mathrm{y}\left[\mathrm{y} \leq_{\mathrm{P}} \mathrm{x} \wedge \mathrm{R}\left(\mathrm{y}, \mathrm{e}^{\prime}\right)\right]\right]$
The subobjects that correspond to subevents are unique.

(8a) and (8b) together with uniqueness of events (8c) and uniqueness of objects (8d) define strict incrementality (see Krifka 1998, p.213, (51)). It presupposes that the entities to which the relation $R$ is applied have non-trivial proper parts. For example, make a dot is telic by virtue of having atomic/countable events in its denotation, but it is not strictly incremental, because its denotation has no proper temporal parts, and a dot itself has no spatial proper parts. Cp. also: recognize, spot; find (a key), lose (a key); burst, explode.

The mappings in (8a-d) are stated in terms of relations between the event argument $e$ and the incremental argument $x$. Such relations are standardly taken to characterize thematic relations $\theta$. The incremental argument that is realized as the direct object or subject corresponds to the Incremental Theme argument (in the sense of Dowty 1991, and 'Gradual (or Successive) Patient' in Krifka 1986, 1992). Verbs are composed with their Incremental Theme arguments following the principle of aspectual composition (see Krifka ibid.). From the above observations it follows that telicity and incrementality are fully independent of each other, as (10) states (see also Filip 1993/99).

(9) Aspectual composition: In simple clauses describing particular eventualities, a quantized Incremental Theme argument of a dynamic predicate $\mathrm{V}$ yields a quantized (telic) verbal predicate. A homogeneous Incremental Theme argument generates homogeneous (atelic) verbal predicate. 
(10) i. Telicity does not require incrementality (cp. to make a dot, to burst).

ii. Incrementality does not guarantee telicity (cp. Ivan ate soup for ten minutes).

Now, the lowest level at which telicity is relevant to grammatical processes is that of the lexical category $\mathrm{V}$, at which verb meanings are specified. The next higher level is the phrasal level of VP (or V'), the level of aspectual composition (9), and in general 'compositional telicity' (also roughly 'inner aspect'). At this level, the properties of the argumental NPs/DPs and of adverbial modifiers, among others, determine whether the VP is telic, whether it describes what counts as one atomic event. The highest level is the IP level, at which the operators of the grammatical aspect (also 'outer aspect') are located. They are expressed by overt functional heads, such as the progressive $I N G$ in English and the imperfective suffix in Slavic languages (see Filip 2000, Kratzer 2004). They take scope over telic and atelic predicates, which are largely (though not exclusively) expressed by syntactic constituents at the VP level. Following Carlson (2003), I also assume that the VP syntactic level corresponds to the context-free level of interpretation of event semantics ('event semantics' in Carlson's narrow sense). The syntactic IP level corresponds to the standard level of propositional semantics.

\section{Germanic Languages}

It is undeniable that articles, possessive pronouns, certain quantifiers or the accusative suffix in the direct object NP/DP in Germanic languages are often correlated with certain patterns of interpretation related to the telicity of the VP. However, I will argue that VP telicity is not derivable just from the overt morphology of its direct object and the syntactic properties of the functional structure that defines a telic VP. Rather, the telicity of the VP depends on the presence of the incremental argument providing the quantity criterion $Q C$ for the application of the expressed telic predicate (see (5) above). The identification of a suitable incremental argument in turn may depend not only on what is encoded by the verb and its arguments, but also on world knowledge and pragmatic principles of interpretation.

Let us first consider examples in (11). (11a) is telic, even though it contains the bare direct object gold. (11b) and (11c) are atelic, even though their direct objects contain the definite cardinal quantifier three and the definite article the. Obviously, the presence of an overt determiner in the direct object argument is neither a necessary nor a sufficient condition for the telicity of the VP.

(11) a. On January 24, 1848 James Marshall found gold at Sutter's Mill, touching off the California gold rush.

b. John carried three pears / the pears $\left(^{*}\right)$ in five hours / for five hours.

c. John stirred the soup $(*)$ in ten minutes / for ten minutes.

How do we motivate the observation that (11b) and (11c) are atelic but (2a) and (3a) telic, although they are all structurally alike? One of the weaknesses of syntactic approaches to telicity is that this question has no clear answer, or it is considered to lie outside of the grammar of natural languages. On the semantic approach to telicity advocated here, this contrast is fully expected and systematically motivated. It illustrates the crucial role played by the meaning of the main lexical verb as one of the factors that determines the telicity of complex verbal predicates. (2a) and (3a) are telic, because their quantized direct objects three pears and the soup stand in the Incremental Theme relation to the verb ate, and are composed with it following the principle of aspectual composition in (9). $(11 \mathrm{~b}, \mathrm{c})$ are atelic, because the denotations of their quantized direct objects three pears and the soup are not incrementally related to the denotation of carried and stirred, 
respectively.

Another problem concerns the assumed link between telicity and definite descriptions. The presence of a definite determiner in the direct object DP is taken to be correlated with the countability feature (see van Hout in press) or the 'quantity' feature (see Borer 2004), which in turn are taken to enforce the telic interpretation of a VP. However, ate the soup in (2a) freely alternates between the telic and atelic interpretation, as evidenced by its compatibility with either type of the diagnostic temporal adverbial in ten minutes and for ten minutes. Therefore, the proposal that all definite descriptions grammatically function as 'quantity' expressions, as Borer (2004) does, cannot be upheld. The 'quantity' interpretation of definite descriptions (in isolation) is not due to the definite determiner, but rather to the lexical semantic properties of the common noun. For example, the pear expresses a 'quantity' (in Borer's sense) or quantized (in Krifka's sense) predicate, because the lexical meaning of pear fully determines what counts as a single atomic unit in its denotation. In contrast, a mass noun like water or a plural noun like pears takes its denotation from a non-atomic semi-lattice, the denotation domain of homogeneous predicates. When combined with the, it yields a definite description that on its own still expresses a homogeneous predicate, according to (7a). It is, therefore, unsurprising that the water in When I turned the tap on, the water rushed out of the faucet denotes some known water stuff, due to the and the association with the previously mentioned tap, rather than a specific quantity of water (see also Jackendoff 1990, p.101 for observations). In addition, "the asserts neither universality nor distributivity nor any particular cardinality" (see Partee 1995, p.581). This also means that the does not assert anything about vague quantity, unlike many, more than a hundred, millions, contrary to Borer's suggestion (Book I, Chapter 6; Book II, Chapter 15, fn. 6). As Partee (1995, p.581) and others argue, the is not an expression of quantification. If a definite description consisting of the and a mass or plural noun has a 'quantity' interpretation it is not determined by the grammar, but rather depends on pragmatic principles of interpretation and world knowledge. In our example (2a) Ivan ate the soup, the soup may refer not only to some contextually specific soup stuff but also to some unique portion of it, delimited by some contextually specified container, some bowl or cup. The observation that ate the soup in (2a) alternates between the telic and atelic interpretation straightforwardly follows from the principle of aspectual composition in (9), if we assume that the soup has a quantized ('quantity') interpretation or a cumulative one, depending on the context, and that it is linked to the Incremental Theme.

In general, the telicity of a verbal predicate, including the selection of the suitable incremental argument providing the quantity criterion $Q C$ for its application, does not just depend on what is explicitly coded by its head verb and arguments, but also on pragmatic principles of interpretation and world knowledge. For example, there is a large class of transitive verbs that head VP's alternating between the telic and atelic interpretation depending on the context. Among the many examples given in Kratzer (2004) are: examine, read, roast, iron, bathe, wash, comb, fry, polish, explain, pollute, control, cover, insulate, test, decorate, describe, drain, mop, check. Let us illustrate this point with examine in (12), previously discussed in Filip (1993/99). The telic interpretation of (12) is felicitous if the interpreter knows that (12) applies to a situation in which the doctor follows a certain established examination procedure, which is related to the patient and consists of a finite set of successive steps. For every step in the examination procedure (= incremental argument), there is a corresponding part of the examination event, and vice versa.

(12) The doctor examined the patient in an hour/for an hour.

Filip 1993/99 
Although there is a link between telicity and direct object in so far as the incremental argument providing the quantity criterion $Q C$ for the application of a telic predicate is often expressed by the direct object (2a) or closely tied to it (12), we cannot ignore that it may also be expressed by the subject argument of an inherently transitive verb (see Verkuyl 1972, Filip 1990, 1993/99, Dowty 1991, Jackendoff 1996, for example). For example, as Dowty (1991, p.571) observes, in (13a), the Incremental Theme is the path across the desert, implied by the direct object the desert, but in (13b), the Incremental Theme is the body of the turtle, which is expressed by the subject. Among the inherently transitive verbs whose subject argument may be incrementally construed, provided a suitable context and world knowledge, are cross, penetrate, permeate, pass, skirt.

(13) a. She crossed the desert in a week.

Dowty 1991

b. At the turtle race, the winning turtle crossed the finish line in 42 seconds.

The link between telicity and the subject argument (of an inherently transitive verb) lies outside the scope of syntactic approaches which restrict the expression of telicity to the functional projection right above the VP. Most importantly, it cannot be argued that the Incremental Theme argument in (13b) originates in the direct object position at some level of syntactic description and then moves into the surface subject position. If we resorted to such an ad hoc movement strategy, we would lose the empirical force of the generalization that links telicity to the direct object (see Dowty 1991, 571, fn. 15 and also Filip 1990, 1993/99).

Given that the identification of the incremental argument depends on semantic, world knowledge and pragmatic factors, there will be a variety of incremental arguments, and consequently mappings between their part structure and the part structure of an event. We may distinguish four main types:

(14) mapping between the part structure of the event and

i. the temporal trace of the event (ivalk for an hour);

ii. the parts of a structured quantity of the denotation of the Incremental Theme subject or object (eat three pears, the turtle crossed the finish line);

iii. the locations of the moving entity on the structured path in the spatial or some metaphor-based domain (cross the desert, walk to the post office, perform a sonata);

iv. the degrees of a property scale associated with one of the event participants (cool the iron from $90^{\circ} \mathrm{C}$ to $20^{\circ} \mathrm{C}$, turn Bill into a frog).

The part structures in (i-iv) are reducible to one general topological part structure, as proposed by Krifka (1998): namely, a one-dimensional axis that is non-branching, noncircular and directed, and which allows us to represent incremental changes in various domains in terms of a 'motion' through its ordered points or segments. (For related proposals see Tenny 1987, 1994, Filip 1993/99, 2005, Ramchand 1996, Jackendoff 1996, Hay, Kennedy \& Levin 1999.)

To conclude, first, the telicity data discussed in this section raise the question whether the components of the meanings of verbs, most prominently the assumption that certain verbs have meanings that involve a homomorphism between their incremental argument and event argument, can be adequately recast in syntactic structures; and if so, the next question to ask is whether the explanation of the telicity phenomena requires appeal to syntactic structures, as the only explanatory mechanism or in combination with semantic and possibly also pragmatic factors. This ultimately is an empirical question and relevant to the nature of lexical representations in sentence processing (see also Filip 2002 et al.). Second, articles, possessive pronouns, certain quantifiers or the accusative suffix in the 
direct object NP/DP in Germanic languages cannot be claimed to encode telicity, because they are not consistently and in all of their occurrences linked to the telicity of a VP, but rather may serve as just one among other contributing factors that together result in a telic interpretation of a VP. From this it follows that the semantic and functional overlaps observed between English sentences like (2a) and Russian perfective sentences like (2b), for example, cannot be generalized to direct correspondences between the definite article in the direct object DP in Germanic languages, on the one hand, and perfective aspect of a verb or verbal prefixes in Slavic languages, on the other hand. Similarly, we must reject any direct cross-linguistic correspondences between possessive pronouns, accusative case marking or quantifiers in Germanic languages and the perfective aspect or prefixes in Slavic languages. Consequently, cross-linguistic empirical studies, including acquisitional ones, predicated on such general cross-linguistic correspondences in surface morphology suffer from a basic design flaw.

\section{Slavic languages}

In this section I will present evidence that challenges the view of Slavic aspect proposed by the syntactic telicity parameter. First, the specifier head agreement between the functional head linked to perfective aspect and the direct object overgeneralizes: In its unconstrained form, it wrongly predicts that all direct objects of perfective verbs are caught in the telic specifier head agreement. At the same time, in those cases in which perfective verbs do indeed have effects on the form and interpretation of their direct objects, the syntactically-based agreement mechanism does not allow us to predict the diversity and full range of such effects, which are modulated by the fine-grained lexical properties of perfective verbs and their prefixes. Second, direct object DP's interact with imperfective verbs, and contribute to the expression of telic predicates by imperfective VP's.

Perfectivity, Prefixes and Direct Objects. As a point of departure, I will take Borer's (2004) proposal, because it provides the most detailed and sophisticated syntactic account of the relevant Slavic data. Its main claims are summarized in (15) (Borer's (38) in Borer 2004, Book II: Chapter 15):

(15) a. Bare NP's must be strong: their interpretations correspond to DP's with the definite article the or the indefinite $a$ with the widest scope.

b. Cardinality expressions and weak quantifiers may not receive a strong interpretation.

c. Strong quantifiers are impossible.

d. Non-quantity interpretations are impossible.

e. Generic interpretation for bare NPs is impossible.

However, each of the generalizations in (15) is violated by some Slavic data. First, contrary to $(15 \mathrm{c})$, strong quantifiers can occur in perfective-telic structures, as the Czech example (16a) shows, in which the telic interpretation is reinforced by the resultative phrase 'until nice and crusty'.
Peter CUL-baked
každou housku pěkně do křupava. each.SG.ACC roll.SG.ACC nicely to crusty
a. Petr $\underline{\mathbf{u}}-$ pekl $^{\mathrm{P}}$
'Peter baked each roll until nice and crusty.'
b. Na-trhala ${ }^{\mathrm{P}} \quad$ *každou jahodu.
CM-picked.FEM *each.SG.ACC strawberry.SG.ACC
'*She picked a lot of each strawberry.'


The strong quantifier 'each' in (16b) is not excluded by the perfective-telic structure per $s e$, but rather by the lexical semantic properties of the cumulative prefix $n a-$ (see Filip 2005 and below).

Second, although (15b) holds as a strong preference, as also Bittner and Hale (1995, p.99) observe, it can be overridden in a suitable context, as (17) taken from Polish shows.

(17) Dzieci tworzą koło. Jedno dziecko wejdzie ${ }^{P}$ do środka i pokazuje, jak się czuje ...

'The children are forming a circle. One child goes into the middle and is showing how it is feeling ...'

Polish

Third, as far as (15e) is concerned, generic statements are compatible with the semantics of perfectivity (see Filip \& Carlson 1997; for Russian examples see Forsyth 1970 , p.120, for instance), and bare nominal arguments of perfective verbs may have a generic interpretation, as the Czech example (18) shows.
Každý rok na začátku dubna přiletí ${ }^{P}$
every year on beginning april in.fly.PRES.3PL
'Every year, swallows arrive early in April.'
vlaštovky.
Czech

Fourth, (15a) covers (but is not restricted to) the well-known correlation between perfective verbs and referentially specific nominal arguments (see Wierzbicka 1967, Forsyth 1970 and Chvany 1983, to name just a few). On Borer's account, this 'strong' reading is enforced for bare direct objects, when the prefix on a perfective verb is the sole assigner of the 'quantity' value to $A S P_{Q}$ and to the direct object in its specifier. Hence, all the direct objects in (19a-b) are predicted to have the 'strong' interpretation, but in fact, only those in (19a) do.
a. Ivan $\underline{\mathbf{s}}-\mathrm{jel}^{\mathrm{P}}$ Ivan CUL-ate zakuski i sup. snack.PL.ACC and soup.SG.ACC 'Ivan ate up (all) the snacks and (all) the soup.'
b. Ivan $\underline{\mathbf{s}}-$ jel $^{\mathrm{P}}$ jabloko. Ivan CUL-ate apple.SG.ACC 'Ivan ate (up) a/the (whole) apple.'
c. Kto-to yabloki pri-nes ${ }^{\mathrm{P}}$, no ya prosil ${ }^{\mathrm{I}}$ gruši. somebody apple.PL.ACC GOAL-brought but I asked pear.PL.ACC 'Somebody brought apples but I asked for pears.'
d. Tam na-stroili ${ }^{\mathrm{P}}$ mnogoetažek v stalinskom stile / *dom /*doma. there CM-built many.floor.PL.GEN in stalinist style / *house.SG.ACC / ${ }^{*}$ house.SG.GEN 'They built a lot of highrises in a stalinist style / *a house there.'

(19a) asserts that the event culminated when some specific snacks and some specific portion of soup were consumed in their entirety. The interpretation of the bare arguments 'snacks' and 'soup' here comes close to the interpretation of English NPs with the definite article the, understood as referential definites, in combination with the universal quantifier all or some totality expression like whole, entire or total. The latter implies the exclusion of any 'non-quantity' interpretation, in compliance with Borer's (15b). But contrary to $(15 a)$, in (19b) and (19c), the direct objects need not have a 'strong' interpretation. In (19d), the direct object is precluded from having a 'strong' interpretation (i.e., a referentially specific or a wide-scope indefinite interpretation) by the measure prefix $n a-$. In addition, the direct object in (19c) may have a 'non-quantity' interpretation, contrary to (15d). Under the most natural interpretation of (19c), what matters for communicative purposes is the fact that some objects were brought that fit the description 'apples', but their exact identity and quantity is irrelevant. 
Even a brief examination of examples like those in (16)-(19) raises the question whether the influence of perfective verbs on their direct object arguments can be motivated in purely syntactic terms. Within the event-semantic approach to telicity presupposed here, such data can be accounted for by one general semantic constraint, formulated in (20), and some additional assumptions independently needed for the interpretation of nominal arguments in natural languages.

(20) Homogeneous nominal predicates undergo a type shift from the predicative type $<e, t\rangle$ into the maximal (referentially specific) interpretation of the argumental type $e$ via the $\sigma$-operator, when they function as Incremental Theme arguments of perfective verbs, provided they are not in the scope of measure, quantificational or modal operators introduced in the same clause.

Since I have discussed (20) and its implications elsewhere (see Filip 1996, 1993/99, 2004a,b, 2005), in what follows I will provide a brief summary illustrated with examples in (19). First, the homogeneity constraint in (20) captures the contrast between (19a) and (19b). Only the homogeneous arguments in (19a) are interpreted as referentially specific, but not the quantized argument in (19b), even though (19a) and (19b) are headed by the same perfective verb sjel 'he ate up' that denotes culminated events, hence it is telic. An eating event culminates with respect to some maximal quantity of whatever is consumed, which is denoted by the Incremental Theme argument. The maximal individual in its denotation thus specifies the quantity criterion $Q C$ for the application of a telic predicate (see (5) above), and with respect to which the culmination requirement of a perfective verb like sjel 'he ate up' is characterized. Similarly as Kratzer (2004), I propose we distinguish between the culmination condition specified by the quantity criterion $Q C$ and the culmination requirement. The culmination condition states what has to be the case if the event in question culminates, but it does not imply culmination itself. If the Incremental Theme argument is inherently homogeneous, as in (19a), the $\sigma$-operator (see Sharvy 1980, Link 1983) picks out the unique maximal entity, which satisfies its description in a given domain of discourse: namely, the maximal sum of ordinary individuals in the standard case of plurals like zakuski 'snacks', and the maximal fusion of all the quantities of stuff in the standard case of mass nouns like sup 'soup'. The $\sigma$ operator shifts a common noun like the Russian zakuski 'snacks' from its basic meaning snacks', which is of the predicative type $\langle e, t\rangle$, to the maximal, and hence referentially specific, interpretation $\sigma^{*}$ X.snacks'(x) '(all) the snacks' of the individual type $e$, the appropriate argumental type. I propose that the $\sigma$-operator is a part of a logical representation of a perfective verb like sjel 'he ate up': namely, a local operator over the variable introduced by its Incremental Theme argument, provided it is homogeneous. This makes sense given that the unique maximal (i.e., referentially specific) interpretation of a homogeneous Incremental Theme argument is enforced by the lexical and aspectual properties of a perfective verb like sjel 'he ate up' and nothing else. The $\sigma$-operator is here defined only for proper plural (in Link's sense 1983, 1987) and mass predicates.

In (19b), we see that the singular count noun 'apple' need not have a referentially specific interpretation, because its contextual anchoring is not required, when it characterizes the quantity criterion $Q C$ (culmination condition) and culmination requirement of an incremental perfective verb like sjel 'he ate up'. Count nouns like 'apple' denote atomic entities that can be taken as having an inherent cardinality measure ONE-NATURAL-UNIT as part of their lexical structure, which amounts to an inherent quantity criterion $Q C$. Their argumental interpretation in perfective sentences like (19b) 
is derived from predicative interpretation by means of one of the two covert type-shifters, $\exists$ and $\iota$, depending on the context (see also Filip 2005).

Second, (20) sharpens the well-known correlation between perfective verbs and referentially specific nominal arguments by restricting it to perfective verbs and their Incremental Theme argument. Other arguments of perfective verbs need not be interpreted in this way: cp. Russ. Ivan po-mešal (pf.) sup - 'Ivan stirred (the/some) soup', 'Ivan did some soup-stirring', Kak to raz ya $\underline{u}$-viděl (pf.) devuški na ulice - 'Suddenly, I saw (some) girls on the street.' Now, just like sjel 'he ate up' in (19a), prines 'he brought' in (19c) denotes culminated events, it is telic. However, in (19c), the culmination requirement of prines 'he brought' is related to the maximal extent of the implicit path associated with the described motion event and its goal, and not to the maximal individual that satisfies the description of the direct object 'apples'. Therefore, 'apples' in (19c) need not have the unique maximal, or 'strong' (in the sense of Borer's (15)) interpretation. Instead, it is here most likely interpreted as a property-denoting indefinite, which amounts to a non-quantity interpretation, contrary to both (15a) and (15d). This naturally follows assuming that 'apples' does not stand in the Incremental Theme relation to the perfective verb prines 'he brought'.

Third, according to (20), the referentially specific interpretation of homogeneous Incremental Theme arguments of perfective verbs may be preempted if they are in the scope of a measure, quantificational or modal operator introduced in the same clause. Such operators may be introduced by verbal prefixes. This point is illustrated by the difference between $s$ - in (19a) and $n a$ - in (19d). They are attached to the imperfective verb stems 'eat' and 'build', respectively, which belong to the same general class of verbs taking an Incremental Theme argument, and yet only the homogeneous Incremental Theme argument in (19a) must be interpreted as referentially specific, but in (19d) it is enforced to have a non-specific indefinite interpretation, contrary to (15a). One way of analyzing the use of $n a$ - in examples like (19d) is in analogy to the semantics of nominal measure phrases, as I propose (see Filip 2000, 2005 and elsewhere). It may be represented as in (21):

(21) $N A_{C M} \rightarrow \operatorname{MS}\left\{\lambda \mathrm{x}\left[\mu_{\mathrm{C}}(\mathrm{x})=\mathrm{n}_{\mathrm{C}}\right]\right\} \wedge \mathrm{n}_{\mathrm{C}} \geq \mathrm{C}_{\mathrm{C}}$

Maximally separated (MS) sums of $x$ to the amount of some contextually specified number $n_{C}$ such that there are $n_{C}$ of contextually specified measure units $\mu_{C}$ and $n_{C}$ meets/exceeds the contextually specified standard of comparison $C_{C}$.

Presupposition: $C_{C}$ is considered to be a high estimate.

In combination with the imperfective stem like 'build', $n a$ - derives a perfective verb with the meaning of approximately 'to build a lot of $x$ ' or 'to build a (sufficiently/exceedingly) large quantity of $\mathrm{x}$ '. The variable $x$ is assigned as its value some plural or mass individual introduced (i) by the Incremental Theme argument, 'highrises' in (19d), or (ii) by the Theme argument, understood as designating the moving participant in a described eventuality. (Examples can be found in Filip 2005.) Proposing that the prefix $n a$ - has the semantics of a measure phrase in verbs like nastroit' 'to build a lot of $\mathrm{x}$ ' has the advantage that it allows us to straightforwardly motivate two important properties of the nominal argument that $n a$ - targets. First, it cannot be a singular count argument, as (19d) shows. Second, since measure phrases generally behave like indefinites (see also Landman 2004 and elsewhere), the argument targeted by $n a$ - cannot be strongly quantified, as we see in (16b). It can also be shown that the nominal argument targeted by a measure prefix like $n a$ - is scopally inert, i.e., the measure prefix $n a$ - and the nominal argument targeted by it must take scope with the predicate, and cannot take scope over any other scope taking 
operator or quantifier in a sentence. This behavior is generally taken to be characteristic of non-specific indefinites, including those that are incorporated. Hence, properties of prefixes with a measure function bear on the general discussion regarding the crosslinguistic variation in the semantics (and syntax) of NP's/DP's, and the semantic typology of indefinites in particular (see Farkas 2002, Chung and Ladusaw 2003, Farkas and de Swart 2003, Carlson 2003, to name just a few recent studies).

The above observations have two important theoretical implications, which are directly relevant to the role of the system of prefixation in the grammar of Slavic languages. First, Slavic verbal prefixes have uses related to the notion of 'quantity' in the widest sense, which directly concern some quantitative dimension of an expressed event, often denoted by one of the verb's nominal arguments. Such quantity uses can be specifically related to cardinality/measure, distributivity or totality (maximality exhaustivity), and their behavior can be characterized in terms of the following working hypothesis, as Filip (2001) proposes:

(22) Verbal prefixes in Slavic languages may express as a part of their meaning cardinality/measure, distributivity or totality (maximality, exhaustivity). They do not express proportional notions of quantification.

The hypothesis implies that verbal prefixes in Slavic languages do not require tripartite structures for their representation, unlike proportional or essentially quantificational (strong) operators.

Second, the observation that Slavic verbal prefixes have uses involving notions related to quantity (in the widest sense) provides an independent additional argument in support of the claim that the system of Slavic verbal prefixation is best not viewed as an inflectional system of perfective marking. (For other arguments see Spencer 1991 and Filip 1993/1999, 2000.) For example, Borer (2004) proposes that Slavic prefixes phonologically spell out the (functional) telic head feature of $A S P_{Q}$, uniformly interpreted in terms of the 'quantity' feature, much on a par with the way in which the past tense inflection -ed in English is the phonological spell out of a past tense head feature. However, clear instances of inflectional morphemes in natural languages are neutral with respect to quantity in space or time (see Talmy 1985 and elsewhere). Moreover, notions related to cardinality/measure, distributivity and totality (maximality) are typically conveyed by determiners and measure expressions within NP's/DP's, which are not inflectional in nature. Instead, in a number of typologically unrelated languages, such notions are conveyed by a variety of lexical operators that are directly applied to a verbal lexical predicate (see Partee 1995, Bach et al. 1995 and references therein). They typically have other additional content (spatial, temporal or manner related, for example) and induce morphological, syntactic and semantic changes in the argument structure of the predicate (see Partee 1995). Slavic verbal prefixes are operators of this type. They have all the hallmark properties of derivational morphemes, which clearly set them apart from inflectional morphemes in general, and from inflectional morphemes used for the expression of grammatical aspect, such as the imperfective suffix in Slavic languages or the French imparfait and passé simple suffixes.

There are also intriguing similarities between the Slavic and Germanic system of prefixation suggesting that the decisive parametric difference between Slavic and Germanic languages in the encoding of telicity cannot be located at the level at which prefixes are applied to verb stems. Once we examine the class of Slavic prefixes as a whole, we see that there is no more reason for Slavic prefixes to be taken as spelling out the functional head feature 'quantity' or '[telic]' than there is for Germanic prefixes. Put differently, there is no systematic correlation between Slavic prefixes and telicity of verbs 
(see also Filip 2001, 2004a,b), just as there is no systematic correlation between Germanic prefixes and telicity of verbs (as Kratzer 2004 shows for German). Let me just briefly mention two arguments. First, let us compare Russian examples in (23) with German ones in (24):

a. $\frac{\text { Po-stroil }}{\mathrm{P}}$ dom u morya.
CUL-built house.SG.ACC at sea
'He built a house by the sea.'

a. die Blätter be-schreiben the.PL.ACC page.PL.ACC BE-paint 'to cover (all) the pages with writing' b. V vašix slovax ja po-čuvstvoval ${ }^{\mathrm{P}}$ uprëk. in your words I PO-felt reproach.SG.ACC 'I felt a reproach in your words.'

b. neue Anwälte be-auftragen new.PL.ACC lawyer.PL.ACC BE-commission 'to commission new lawyers'

The result of applying the Russian po- to a verb of creation, as in po-stroil 'he built' in (23a), is standardly taken to be telic. Similarly, the German be-in (24a) is attached to the verb of creation schreiben 'to write' and derives a telic verb. But in the Russian (23b) (taken from Rassudova 1984) and the German (24b), po- and be-form a prefixed verb that is not telic. The prefixes po- and $a b$ - illustrate a behavior that is characteristic for prefixes in Slavic and Germanic languages as a whole class: namely, they have uses in which they derive telic verbs, but also uses in which they derive verbs that are not telic. Slavic and Germanic prefixes are also alike in so far as they exhibit polysemy and homonymy, not all prefixes attach to all verbs, their effects on the lexical semantics of verbs are often unpredictable, the combination 'prefix+base' is often not transparently compositional, but often partly or fully lexicalized.

Second, what has not been integrated into syntactic parametric accounts is the observation that Germanic languages have a way of encoding the VP telicity by the prefix on the verb, and not by the DO-DP, whereby the DO-DP must participate in the 'telic concord' with the verb, and not vice versa. For example, in (24a), the telicity feature is directly assigned by $b e$ - to the prefixed verb be-schreiben 'to cover (all) the $x$ with writing', which in turn enforces the maximality interpretation of the Incremental Theme argument 'pages', just as the Russian prefixed verb sjel 'he ate (up)' does with respect to its Incremental Theme zakuski 'snacks' in (19a). Since German has overt articles, the maximal interpretation of the direct object is obligatorily marked by the definite article die 'the'. In English, certain particle verbs have a similar maximality effect: cp. He drank up (all) the wine vs. *He drank up wine vs. He drank (the) wine. What we observe in German is thus the same type of unidirectional agreement relationship between the verb and its direct object DP that is taken to be restricted to Slavic languages only. Now, it could be objected that it is the definite article die 'the' in the direct object DP, and not the prefix be-, which is the source of VP telicity. Such an objection can be easily invalidated. The absence of the prefix sanctions the omission of the definite article, as we see in Briefe schreiben 'to write letters'. It also sanctions the alternation of the VP between the atelic and telic interpretation, even if the definite article is present: cp. die Briefe stundenlang /in einer Stunde schreiben 'to write the letters for hours / in an hour.' Recall that definite descriptions on their own cannot trigger the telicity of the VP, as has been argued above.

We also observe that this type of agreement relationship between verbs and their direct objects in Germanic languages requires the same semantic grounding as in Slavic languages: namely, it only applies to verbs and their Incremental Theme arguments, and not to other arguments. In contrast to (24a), in (24b) we see that be-auftragen 'to commission' does not enforce the maximality interpretation of the direct object requiring the presence of the definite article. (24b) does not (necessarily) mean 'to commission (all) the new lawywers' that there are in the domain of discourse. The lack of the maximality 
interpretation can be here motivated along similar lines as in Slavic languages: beauftragen 'to commission' is atelic and Anwälte 'lawyers' is not linked to the Incremental Theme.

Telicity of Imperfective VP's in Slavic languages. Let us first consider the contrast between Russian imperfective sentences in (25) and (26).

(25) a. Ivan jest ${ }^{\mathrm{I}}$ grušu. Ivan eats pear.SG.ACC 'Ivan eats / is eating a/the/some pear.' b. Ivan vidit ${ }^{\mathrm{I}}$ každoj) stakan vody / tri gruši.

I. sees (each) glass.SG.ACC water.SG.GEN / three pear.PL.ACC

'Ivan (right now) sees each glass of water / a/the/some glass of water / three pears.'
Ivan jest ${ }^{\mathrm{I}}$ ves'
$\sup$
/ tri gruši
/ tarelku supa.
Ivan eats whole.SG.ACC soup.SG.ACC / three pear.SG.ACC / plate.SG.ACC soup.SG.GEN 'Ivan eats a/the whole portion of soup / three pears / a plate of soup.'
(\#'... is eating ...')

Although Russian imperfectives can generally be used to express statements about ongoing particular eventualities, i.e., can have a progressive interpretation, this interpretation is unproblematic only in (25a,b), while in (26) it is considered odd or even ungrammatical (see Jakobson 1936, Paducheva 1998, 2003, among others). Speakers who accept it in (26) also observe that it requires considerable interpretive effort. Instead, (26) is naturally understood as expressing a generic habitual statement. For example, Ivan jest tri gruši in (26) is readily interpreted as 'Ivan eats three pears (everyday, usually, etc.)'. This interpretation strongly suggests that Ivan finishes eating all three pears at each relevant occasion from which one infers the expressed regularity. But this means that the logical representation of the above sentence will have the generic operator taking scope over a telic predicate, approximately $\lambda \mathrm{x}, \mathrm{e}\left(\right.$ eat' $^{\prime}(\mathrm{e}) \wedge$ three-pears' $\left.(\mathrm{x}) \wedge \mathrm{INC} . \mathrm{TH}(\mathrm{e})=\mathrm{x}\right)$.

The existence of a telic predicate in the logical representation of a Russian imperfective can be empirically confirmed by the observation that it is compatible with time-span adverbials like $v$ den' 'in a day', as we see in $(27 a, b)$. (27a) has a generic dispositional meaning: namely, if you give Ivan a bottle of vodka, he can drink it all in one day, on any given suitable occasion. (27a) contains the secondary imperfective verb vypivaet (ipf.) 'drinks (up)', 'is drinking (up)', because some native speakers prefer it to the simple (underived) imperfective verb $p$ 'et (ipf.) 'drinks', 'is drinking' in generic contexts like (27a). (See more below.) (27b) expresses a generalization over a plurality of particular writing events, whereby each involves a different paper in the plurality denoted by the bare plural 'papers', and each paper took one day to complete. $V$ den' 'in a day' here takes scope over a telic predicate: approximately $\lambda \mathrm{x}, \mathrm{e}(\mathbf{d r i n k}$ '(e) $\wedge$ one-bottlevodka' $\left.^{\prime}(\mathrm{x}) \wedge \operatorname{INC} . \mathrm{TH}(\mathrm{e})=\mathrm{x}\right)$ in $(27 \mathrm{a})$ and $\lambda \mathrm{x}, \mathrm{e}\left(\right.$ write'$^{\prime}(\mathrm{e}) \wedge$ one-paper'(x) $\left.\wedge \operatorname{INC} . \mathrm{TH}(\mathrm{e})=\mathrm{x}\right)(27 \mathrm{~b})$. In contrast, in (27c), $v$ den' 'in a day' is ungrammatical, because $p$ 'et vodku 'drinks vodka' cannot be construed as involving a telic predicate in its representation.
a. V den' Ivan p'et / vy-pivaet ${ }^{\mathrm{I}}$
butylku
vodki. in day I. drink.PRES.3SG / PREF-drink.IPF.PRES.3SG bottle.SG.ACC vodka.SG.GEN 'Ivan drinks (is able to drink) a bottle of vodka in a day.'
b. Ivan vsegda pisal ${ }^{\mathrm{I}}$ doklady vodin den'. Ivan always wrote paper.PL.ACC in one day 'Ivan always wrote his papers in one day.'
c. *V den' Ivan p'et
*in day Ivan drink.IPF.PRES.3SG vodka.SG.ACC
*'Ivan drinks vodka in a day.'


Going back to Russian imperfectives like (26), what makes them unacceptable or odd in their progressive interpretation is the presence of a telic predicate of a particular type in their logical representation:

(28) A telic predicate that is generated by means of (i) a quantized Incremental Theme argument (ii) with an overt measure phrase and/or a determiner quantifier, is unacceptable in a sentence with a progressive interpretation, or it reduces the range of its interpretive possibilities.

Notice that overtly measured and quantified direct objects that are not linked to the Incremental Theme license a progressive interpretation of a sentence, as we see in (25b), and singular count Incremental Themes like 'pear' in (25a) do so, as well, even though they form telic predicates. If (28) is correct, it should also apply to sentences formally marked to express progressivity, a subcategory of the imperfective category (see also Comrie 1976). This prediction is borne out by English progressives, as we see in (29):

(29) a. John was eating \#the whole cake / three pears when I arrived.

b. John was eating a pear when I arrived.

c. John was holding three pears / the whole cake when I arrived.

There seems to be a general agreement that a progressive sentence like John was eating the whole cake is odd (see Kearns 1991, p.290 and Zucchi 1999, p.205, fn.15). However, with a special affective emphasis, it is acceptable: cp. Look! He is eating the whole cake! (see also Zucchi 1999, p.206, fn.15). According to Mittwoch (1988), the cardinal quantifier three excludes the sequential reading of 'in the midst of eating of one out of what later turned out to be three pears', but allows for the simultaneous or futurate reading of (29a). (A somewhat different view can be found in Zucchi 1999.) In general, English progressives are not commonly used for the expression of generic statements, unlike Russian imperfectives. The generic interpretation of (29a) is acceptable, provided it has the appropriate affective intonation, most commonly related to reproach or accusation: $\mathrm{cp}$. You are always eating the whole cake by yourself!

Interestingly, Russian and English differ with respect to which type of a quantized Incremental Theme argument will interfere with the progressive interpretation. Ivan $p$ 'et stakan vodky is odd or unacceptable if it is meant to convey what the perfectly acceptable English progressive John is drinking a glass of vodka does (see Paducheva 2003). There will be thus language-particular constraints specifying the details of (28).

Telicity of English predicates like eat the whole cake and eat three pears in the scope of PROG in (29a), is straightforwardly predicted by the principle of aspectual composition (9). I propose it also applies to Russian imperfectives like those in (26), and accounts for their telicity. From this it follows that a Russian imperfective predicate like jest' tri gruši 'to (be) eat(ing) three pears' and its close perfective correspondent sjest' tri gruš 'to eat (up) three pears' share the telic predicate $\lambda x, e\left(\right.$ eat'$^{\prime}(e) \wedge$ three-pears' $\left.(x) \wedge \operatorname{INC} . \operatorname{TH}(e)=x\right)$ (roughly) in their respective logical representations (see also Filip 1993/99 and elsewhere). Claiming that this is not the case would imply that either (i) Russian verbs like jest' (ip.f) and sjest' (pf.) have very different lexical semantic properties than the corresponding English verbs like eat and eat up do, i.e., they do not involve object-event mappings, as defined in (8) (or however else defined), or (ii) Russian quantified DP's like tri gruši have denotations different from the denotations of three pears in English, i.e., they are not quantized. Both (i) and (ii) are highly implausible, and their inclusion into the grammar of Slavic languages would be associated with a high cost and very low explanatory gains. This leads me to the following conclusion (see Filip 1993/99 and 1997 for other supporting arguments): 
(30) a. The result of composing an imperfective verb with a quantized Incremental Theme argument is a telic predicate, following the standard principle of aspectual composition (see (9) above).

b. Imperfective VP's in Slavic languages express telic predicates.

To the extent that one subscribes to the validity of the arguments for the usefulness of the Incremental Theme relation in motivating the influence of perfective verbs on the interpretation of nominal arguments, as proposed in (20) (and similar proposals in Krifka 1986, 1992 and Filip 1993/99), then one should also accept arguments showing that it plays a role in the interaction between imperfective verbs and their nominal arguments.

However, (30a) and (30b) are in principle excluded by the syntactic telicity parameter. For example, in Borer's (2004, Book II, Chapter 15) proposal, all imperfectives are uniformly atelic, and atelicity corresponds to the lack of $A S P_{Q}$. Therefore, there is no syntactic structure over which the requisite agreement relation could be defined to mediate between imperfective verbs and their direct objects. Consequently, any interactions between the two we may observe, as in Russian examples in (26) and (27), are entirely determined by world knowledge and not by the grammar of Slavic languages, as Borer argues. Now, this amounts to delegating the knowledge that characterizes the Incremental Theme relation entirely to pragmatics: For example, the knowledge that the extent of an eaten object is typically incrementally tied to the extent of an eating event, but the extent of a stimulus object is not necessarily tied to the extent of a perception event in this way.

To this it may be replied that our understanding of how we classify states of affairs as an eventuality of a certain type, an eating, a seeing, a climbing, a laughing, is constitutive of an eventuality type in the formal theory of event semantics. The classification into eventuality types is directly related to our knowledge about how participants normally, typically function in given eventualities. A certain subset of such relations between participants and eventualities is standardly taken to characterize thematic relations, and partly motivate the membership of verbs in coherent lexical semantic classes. On my account (and also on Krifka's 1986, 1992 and elsewhere; as well as on Dowty's 1991, for example), the Incremental Theme relation in the thematic argument structure of eat, but not see, captures the systematic and grammatically relevant lexical semantic difference between the classes of verbs to which eat vs. see belong. Moreover, if we discard the notion of 'Incremental Theme' from the grammar of natural languages, then the question arises which explanatory mechanism motivates the observed difference between Russian imperfectives like (25) vs. (26), and the difference in the acceptability of time-span adverbials in $(27 \mathrm{a}, \mathrm{b})$ vs. $(27 \mathrm{c})$. If such differences were just a matter of pragmatics, they should be cancelable in a suitable linguistic and/or extra-linguistic context, but they are not.

Perfective and Imperfective Aspect ('Outer Aspect') vs. Telicity ('Inner Aspect'). In contrast to the claim inherent in most syntactically-based parametric accounts of telicity, we have seen that atelicity cannot be taken as the meaning of the formal category of imperfectivity (see $(30 \mathrm{a}, \mathrm{b})$ ) and telicity is best not viewed as the uniform semantics of perfective morphology (see (23b)). Therefore, as I propose (see also Filip 1993/99, 2000, $2004 a, b)$, the semantics of the operators of grammatical aspect, perfective PF and imperfective IPF, is orthogonal to the semantic distinction 'telic vs. atelic'. Their semantic contribution is calculated at the propositional level of semantic description, which corresponds to the syntactic IP level. PF and IPF each can take scope over atelic and telic predicates. The domain of telicity comprises levels of semantic description that are 'lower' than the syntactic IP level (see Section 3 above). 
The IPF operator is phonologically spelled out by the imperfective suffix (see also Filip 1993/99, 2000), as in the secondary imperfective vypivaet 'drinks (up)', 'is drinking (up)' in (27a). Vypivaet (ipf.) is derived from $p$ 'et (ipf.) by prefixation by means of $v y$ followed by the application of the imperfectivizing suffix. As has been argued above, Russian imperfectives like (27a) express telic predicates. Crucially, IPF does not 'neutralize' the quantity criterion $Q C$, or culmination condition, of a telic predicate when it takes scope over it (contrary to Kratzer's 2004 suggestion). In (27a), $Q C$ is encoded by the quantized (measure) Incremental Theme DP 'a bottle of vodka' and the prefix $v y$ - on the verb. IPF, encoded by the imperfective suffix in vypivaet in (27a), concerns the relation between eventuality time and reference time, as also Paslawska \& von Stechow (2003), Kratzer (2004), and others propose.

$$
I P F=\lambda \mathrm{P} \lambda \mathrm{t} \exists \mathrm{e}[\mathrm{P}(\mathrm{e}) \wedge \mathrm{t} \subseteq \tau(\mathrm{e})]
$$

In Slavic, (31) can be viewed as directly corresponding to what is known as the 'general factual' or 'simple denotative' use of imperfective, in which there is no implication of habitual or progressive meaning, and which bolsters the view of imperfective as the unmarked aspect (see also Comrie 1976, p.113). (31) is a semantic default consistent with the more restricted contextually determined progressive and completive interpretations. The latter is arguably implied in (27a), which is naturally understood as having the dispositional generic interpretation: if you give Ivan a bottle of vodka, he can drink it all up in one day.

Although the semantics of imperfectivity is compatible with genericity, genericity cannot be subsumed under imperfectivity, as Filip \& Carlson (1997) argue (contrary to Dahl 1985 and Comrie 1976, and many others). As has also been observed above, the semantics of perfectivity is also compatible with genericity, and perfective sentences can be used to express generic statements. Genericity is a category sui generis and represented by means of the generic operator GEN (see Krifka et al. 1995, Partee 1995, Carlson and Pelletier (eds.) 1995 and references therein), which takes scope over the aspectual operators, IPF and PF. Independently, it has been argued that GEN is a propositional operator, with overt expressions located at the corresponding IP level.

I propose that IPF is also present in the logical representation of simple (underived) imperfectives like $p$ 'et 'drinks', 'is drinking', as in (27a). This implies that simple and secondary imperfectives belong to the same aspectual class, as is standardly assumed (see Zucchi 1999, among many others, but Borer 2004 rejects this assumption), and motivated by distributional and functional parallels between simple and secondary imperfectives. For example, both are compatible with the future auxiliary, generally exhibit the same cooccurrence restrictions with temporal adverbials, and are of ten substitutable in a given sentence without altering its truth conditions, as in (27a). Most importantly, the fact that both simple and secondary imperfectives are commonly and freely used in contexts which exclude the progressive interpretation, as we see in (27a), constitutes one of the most compelling arguments against treating the Slavic IPF on a par with the English PROG, contrary to Zucchi (1999) and Borer (2004), for example, to cite just two among the most recent proposals along these lines.

While a part of Slavic imperfectives is formally marked with the imperfective suffix, Slavic perfectives have no overt formal marker which could consistently and in all of its occurrences be taken as an overt morphological exponent of PF and nothing else. Prefixes do not qualify, given that there are prefixed imperfective verbs, apart from unprefixed perfectives, and given that prefixes are quintessentially derivational morphemes, with rich and idiosyncratic lexical semantic properties. The presence/absence of certain prefixes affects the quantity criterion $Q C$ (culmination condition), and consequently the telicity of 
complex verbal predicates, and not the relation between eventuality time and reference time, which characterizes the grammatical aspect. Therefore, I propose that perfectivity is a property of lexical verbal predicates, evident in the distributional properties of a fully formed verb form by which it is expressed. PF is defined in (32) (see also Paslawska \& von Stechow 2003):

$$
P F=\lambda \mathrm{P} \lambda \mathrm{t} \exists \mathrm{e}[\mathrm{P}(\mathrm{e}) \wedge \tau(\mathrm{e}) \subseteq \mathrm{t}]
$$

If $P$ is telic, because its incremental argument provides a quantity criterion $Q C$ (culmination condition) for its application, combining $P$ with $P F$ amounts to imposing a culmination requirement on $P$ : namely, the whole part structure of the $Q C$ incremental argument was (or will be) subjected to the described event within $t$ (see (19b)). If $P$ is atelic, combining $P$ with $P F$ may amount to imposing a quantity criterion $Q C$ (culmination condition) on it, depending on which derivational process forms the corresponding perfective lexical predicate: cp. Russian kurit' (ipf.) 'to smoke', 'to be smoking' $\rightarrow$ NA-kurit'sja (pf.) 'to smoke one's fill'.

\section{Selected References}

Borer, H. 2004. Structuring Sense. Oxford: Oxford University Press.

Carlson, G. N. 2003. "Weak Indefinites." From NP to DP: On the Syntax and PragmaSemantics of Noun Phrases. Coene, M. and Y. D'Hulst (eds.), Benjamins Publishing, 195-210.

Dowty, D. R. 1991.’Thematic Proto-Roles and Argument Selection.” Language 67, $547-$ 619.

Filip, H. 1993/1999. Aspect, Situation Types and Noun Phrase Semantics. New York/London: Garland Publishing, Inc. [PhD Thesis 1993].

Filip, H. 2004a. "On Accumulating and Having it All: Perfectivity, Prefixes and Bare Arguments." Verkuyl, H., de Swart, H. and A. van Hout (eds.), Perspectives on Aspect. Dordrecht: Kluwer Academic Publishers Group, 125-148.

Filip, H. 2004b. "Prefixes and the Delimitation of Events." Journal of Slavic Linguistics, Browne, W. and B. H. Partee (eds.), Vol. 11, 1, 55-101.

Filip, H. In press. "Measures and Indefinites." Carlson, G. N. and F. J. Pelletier (eds.), Reference and Quantification: The Partee Effect. CSLI: Stanford, CA.

Kratzer, A. 2004. "Telicity and the Meaning of Objective Case." Guéron, J. and J. Lecarme (eds.). The Syntax of Time. Cambridge/Mass.: The MIT Press, 389-424.

Krifka, M. 1992. "Thematic Relations as Links between Nominal Reference and Temporal Constitution.” Sag, I. A. and A. Szabolcsi (eds.), Lexical Matters, 29-53.

Krifka, M. 1998. "The Origins of Telicity." Rothstein, S. (ed.), Events and Grammar. Dordrecht: Kluwer Academic Publishers, 197-235.

Partee, B. H. 1995. "Quantificational Structures and Compositionality.” Bach, E., Jelinek

E., Kratzer, A. and B. H. Partee (eds.), Quantification in Natural Languages.

Dordrecht: Kluwer Academic Publishers Group, 541-601.

Partee, B. H. 1999. "Nominal and temporal semantic structure: Aspect and quantification.” In E. Hajičová, T. Hoskovec, O. Leška \& P. Sgall (eds.), Prague Linguistic Circle Papers, Vol.3., 91-108.

Rothstein, S. 2004. Structuring Events. Oxford: Blackwell Publishing.

Van Hout, A. In press. "Acquiring telicity crosslinguistically: On the acquisition of telicity entailments associated with transitivity." Bowerman M. and P. Brown (eds.) Crosslinguistic Perspectives on Argument Structure: Implications for Learnability. Hillsdale: Lawrence Erlbaum. 